\title{
FREE LITERATURE
}

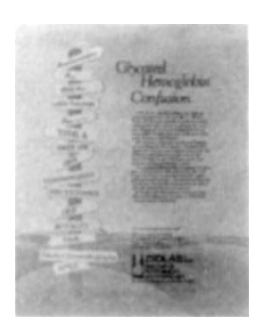

Glycated Hemoglobin Confusion. The latest brochure from Isolab (Akron, $\mathrm{OH}$ ) shines a light onto the confusing terminology pertaining to $\mathrm{GHb}$ assays. Glycated $\mathrm{He}$ moglobin Confusion gives background information and definitions. It also compares the limitations and advantages of various methods for monitoring long-term blood glucose.

Write in 704 on Reader Service Card

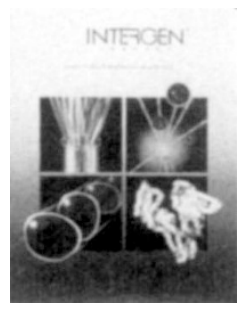

Reagent Reading. Intergen (Purchase, NY) has published a newly revised and expanded product catalog. Along with listing the company's extensive product line, the catalog contains a new account credit application form and a customer order form. It also offers an updated description of Intergen's biopharmaceutical/cell culture, diagnostic, and vaccine reagents.

Write in 707 on Reader Service Card

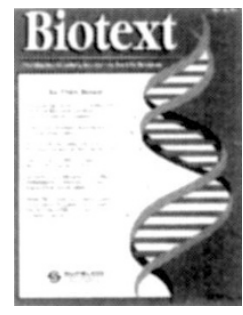

Make Your CElection. The latest issue of Biotext, available quarterly from Supelco (Bellefonte, PA), introduces their CElect family of capillary electrophoresis columns. The first of their kind available commercially, these columns provide an innovative separation method for analyses in many areas including biological, chemical, and pharmaceutical applications. Described are techniques for reducing bitterness in citrus juices, quantifying tricyclic antidepressants in human serum, analyzing neomycin in milk, and separating nucleosides under RPLC conditions.

Write in 706 on Reader Service Card

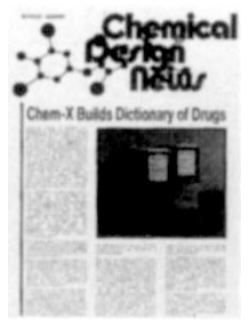

3-D Book News. The latest issue of Chemical Design News from Chemical Design, (Oxford, U.K.) announces the company's intention to build and distribute 3-D versions of the Chapman and Hall Chemical Dictionaries of drug structures with its Chem-X model building system.

Write in 714 on Reader Service Card

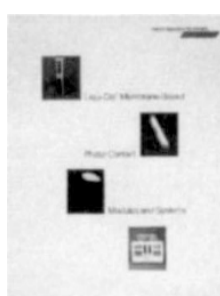

Phase Contacting. Available from Hoechst Celanese (Charlotte, NC), this new brochure entitled Liqui-Cel Membrane-Based Phase Contacting describes the modules and systems available for gas transfer and liquid/liquid extraction applications. Liqui-Cel technology facilitates these applications by a non-dispersive method of contacting two immiscible phases. Immobilizing the interface at pores of microporous hollow fiber membranes provides consistent, stable interface between phases.

Write in 703 on Reader Service Card

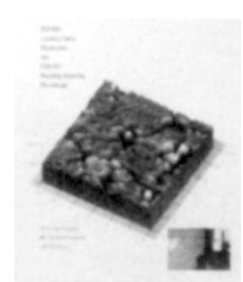

Scanning Microscopes. Park Scientific Instruments (Mountain View, CA) presents its new brochure, Scanning Force Microscope SFM-BD2 and Scanning Tunneling Microscope STM-SA1, which illustrates the capabilities and applications of these instruments designed for bench-top operations. Both provide 3-dimensional imaging on an atomic scale, and are capable of providing quantitative surface profiling and roughness measurements over image fields as large as $125 \times 125 \mu \mathrm{m}$.

Write in 709 on Reader Service Card

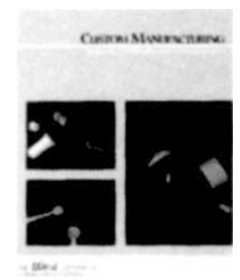

Multi-Material Packaging. A 6page color brochure from West (Phoenixville, PA) highlights the manufacture of custom and small-volume packaging components and systems. Products are constructed from elastomers, plastics, and aluminum for wide usage. Also featured are product development, clean room processing, and fast turnaround.

Write in 702 on Reader Service Card

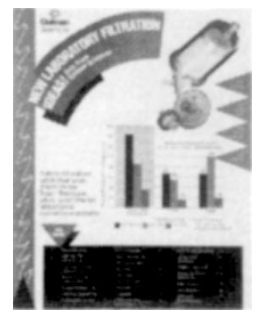

Focus on Filters. The new laboratory filtration catalog from Gelman Sciences (Ann Arbor, MI) features products incorporating its patented Supor membrane, an inherently hydrophilic polysulfone membrane that offers high flow rates, lower extractables, and greater strength than competitive cellulosic (acetate or nitrate) membranes. Filtration products using the Supor membrane include disc, flat disc, syringe (including the Acrodisc PF for highly viscous solutions), the AcroCap filter for 1-10 1 volumes, and capsule filters.

Write in 712 on Reader Service Card

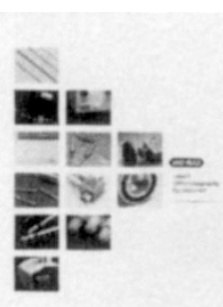

Liquid Chromatography. Bulletin 1538 from Bio-Rad (Richmond, CA) features liquid chromatography accessories including a column heater, single and dual pen chart recorders, sample injectors, and high-pressure dynamic mixers. Also described are a full range of assembled HPLC columns and fittings.

Write in 701 on Reader Service Card 